\title{
Single Nucleotide Polymorphisms of BMP2 Gene Association with Skeletal Class I Crowding: A PCR Study
}

\author{
Kalpesh Sharma ${ }^{1}$, Vijay N Yannawar ${ }^{2}$, Ganesh R Kotalwar ${ }^{3}$, Pallavi Madanshetty ${ }^{4}$, Ishita Grover ${ }^{5}$, Prashant S Lagali ${ }^{6}$
}

\begin{abstract}
Aim and objective: This study is conducted to find the association of BMP2 (bone morphogenic protein 2) gene variant rs1005464 and rs15705 with skeletal class I crowding cases.

Materials and methods: Blood samples from 60 subjects who visited the Department of Orthodontics and Dentofacial Orthopaedics, D.A.P.M.R.V. Dental College, Bengaluru, were taken after written informed consent. These were divided into two groups: group A with 30 subjects having skeletal class I bases with crowding and group B with 30 subjects having skeletal class I bases without visible crowding or spacing ( $\pm 2 \mathrm{~mm}$ ). Around $2 \mathrm{~mL}$ of venous blood sample was procured from cases and controls after careful examination. All the samples were then subjected to polymerase chain reaction followed by DNA sequencing and capillary electrophoresis. BMP2 rs1005464 and rs 15705 gene variants were assessed and Z-Test was used for statistical analysis.

Result: GG $(p=0.001)$ and CC $(p=0.0024)$ genotype of BMP2 gene variant rs1005464 and rs15705, respectively, are significantly associated with skeletal class I crowding cases.

Conclusion: This study concludes that BMP2 variants rs1005464 and rs15705 can be used as genetic markers for skeletal class I bases having crowding.

Clinical significance: Predisposing genetic markers BMP2 can be identified prior and this would help in predicting the probability of potential crowding in the future and this would help in early prevention and intervention of crowding.

Keywords: BMP2 gene, DNA sequencing, Genetic markers, Single nucleotide polymorphism, Skeletal class I.

The Journal of Contemporary Dental Practice (2021): 10.5005/jp-journals-10024-3088
\end{abstract}

\section{INTRODUCTION}

Malocclusion is a developmental problem. It is acknowledged that both hereditary and environmental factors have larger influences on the process of craniofacial development. The comparative importance of environment against hereditary has been controversial since the Angle era. ${ }^{1}$ For most of the malocclusions, the etiology may not be easily known. However, advanced molecular genetics has given newer information about different etiologies in growth and development. ${ }^{2}$

Dental crowding can be defined as a discrepancy between tooth and jaw sizes, which results in malposition and/or rotation of teeth. Dental crowding is not a disease in itself but can be considered a condition that can lead to or promote diseases, such as periodontal disease, dental caries, or temporomandibular joint dysfunction. Nowadays, the prevalence of dental crowding is estimated to range between $30 \%$ and $60 \%$. It is one of the most frequent reasons why people consult an orthodontist, especially given the high aesthetic demand expressed by patients.

Genetic polymorphisms have been effectively reported anomalies in number and forms of tooth-like amelogenesis imperfecta and hypodontia. Single nucleotide polymorphisms (SNPs) are the largely normal genetic mutations in humans, affecting protein expression and functioning, which in that case instigate disease. ${ }^{2}$ Crowding is a common dental anomaly, and, according to the "common disease, communal variant" hypothesis, SNPs are the chief genetic factor for crowding.

Confirmation through population studies, principally family and twin studies, has confirmed that genetic factors have a very significant role in the etiology of malocclusions. ${ }^{3-5}$ On the contrary, studies on siblings and identical twins suggested that
${ }^{1}$ Department of Orthodontics, Albaha Dental Centre, Al Bahah, Kingdom of Saudi Arabia

${ }^{2}$ Department of Orthodontics and Dentofacial Orthopedics, Dr HSRSM Dental College, Hingoli, Maharashtra, India

${ }^{3}$ Department of Orthodontics and Dentofacial Orthopedics, Nanded Rural Dental College and Research Center, Nanded, Maharashtra, India ${ }^{4}$ Department of Prosthodontics, Rural Dental College, Loni, Maharashtra, India

${ }^{5}$ Department of Prosthodontics, MA Rangoonwala College of Dental Science and Research Centre, Pune, Maharashtra, India

${ }^{6}$ Private Practitioner, Belagavi, Karnataka, India

Corresponding Author:Vijay N Yannawar, Department of Orthodontics and Dentofacial Orthopedics, Dr HSRSM Dental College, Hingoli, Maharashtra, India, e-mail: yannawarvijay@gmail.com

How to cite this article: Sharma K, Yannawar VN, Kotalwar GR, et al. Single Nucleotide Polymorphisms of BMP2 Gene Association with Skeletal Class I Crowding: A PCR Study. J Contemp Dent Pract 2021;22(3):248-252.

Source of support: Nil

Conflict of interest: None

environmental factors besides genetic factors have a very important function in the development of occlusion. ${ }^{4}$ Once the hereditary factors are determined and isolated, the clinician may undoubtedly determine and see the environmental factors and pass out the treatment plan according to etiology. ${ }^{6}$

Although it is challenging to find out the genetic part of main malocclusions and dental anomalies because of the polygenic

(0) Jaypee Brothers Medical Publishers. 2021 Open Access This article is distributed under the terms of the Creative Commons Attribution 4.0 International License (https://creativecommons.org/licenses/by-nc/4.0/), which permits unrestricted use, distribution, and non-commercial reproduction in any medium, provided you give appropriate credit to the original author(s) and the source, provide a link to the Creative Commons license, and indicate if changes were made. The Creative Commons Public Domain Dedication waiver (http://creativecommons.org/publicdomain/zero/1.0/) applies to the data made available in this article, unless otherwise stated. 
nature of craniofacial traits, data provided by the human genome project have made it possible to map inherited conditions related to dentofacial development. However, more genetic studies are required to uncover all particular genes which can cause particular skeletal and dental variations. Soon, the faster advancement in molecular genetics may lead to control genetically dentofacial abnormalities and malocclusions. ${ }^{7}$

However, only one study has been conducted to pinpoint the genetic associations of SNPs interrelated to BMP2 (bone morphogenic protein 2), EDA (ectodermal dysplasia-anhidrotic), and XEDAR (X-linked ectodermal dysplasia-anhidrotic receptor) gene with crowding. BMP2 gene is located on the short arm of chromosome 20 between positions 12 and 12.3 (20p12-12.3). ${ }^{2}$ BMP2 gene causes protein formation which belongs to TGF $\beta$ (tumor growth factor) family and induces bone and cartilage formation by acting as disulfide-linked homodimers. Mutations of this gene can lead to anomalies in the development of ectodermal organs, which include sweat glands, hair follicles, and teeth. ${ }^{2}$ However, BMP2 gene mutations are not confined in nature but have their influence on different structures and the outcome too varies. It is said to be responsible for oligodontia, while the present study decodes the probable role in crowding. Thus, this study is aimed to evaluate the association of BMP2 gene variant rs1005464 and rs15705 with skeletal class I crowding cases in Bengaluru, Karnataka population using polymerase chain reaction (PCR) test.

\section{Materials and Methods}

Blood samples from 60 subjects who visited the Department of Orthodontics and Dentofacial Orthopedics, D.A.P.M.R.V. Dental College, Bengaluru, were taken after ethical approval from the ethical committee and written informed consent. This study was conducted in November 2018. After selecting 60 samples, they were divided into two groups based on crowding. Crowding was measured using the irregularity index of crowding.

Group A: 30 subjects having skeletal class I bases with crowding.

Group B: 30 subjects having skeletal class I bases without visible crowding or spacing ( $\pm 2 \mathrm{~mm})$.

\section{Inclusion Criteria}

- Healthy subjects without prior orthodontic treatment.

- Complete permanent dentition age range 21-27 years.

- Skeletal class I relation according to ANB (A point, nasion, B point) angle $\left(0-4^{\circ}\right)$, Wits appraisal $(0-3 \mathrm{~mm}){ }^{8}$ and normal facial profile.

- Not more than $5 \mathrm{~mm}$ of crowding in at least one arch.

\section{Exclusion Criteria}

- Class II molar relation or class II jaw relation.

- Class III molar relation or class III jaw relation.

- Congenitally missing teeth or missing teeth due to caries.

- Retained deciduous teeth.

- Spacing of more than $2 \mathrm{~mm}$.

- Supernumerary teeth.

\section{Methodology}

\section{Collection and Storage of Blood}

Venous blood ( $2 \mathrm{~mL}$ ) was obtained in a test tube having ethylenediaminetetraacetic acid (EDTA) from all subjects and stored for later examination in liquid nitrogen $\left(-70^{\circ} \mathrm{C}\right)$.

\section{Separation of Genomic DNA}

Procured blood was taken in calibrated micropipette into a $1.5 \mathrm{~mL}$ microcentrifuge tube. Later, proteinase $\mathrm{K}(10 \mathrm{mg} / \mathrm{mL})$ and $10 \%$ sodium dodecyl sulfate (SDS) were added and incubated at $37^{\circ} \mathrm{C}$ for $30 \mathrm{~min}$. Then, the mixture was subjected to phenol and chloroform treatment which to dissolve all the proteins and to remove the phenol. In this way, DNA was separated by phenol and chloroform. Later, the mixture was subjected to ultracentrifugation with ethanol (100\% alcohol) at $12000 \mathrm{rpm}$ for $5 \mathrm{~min}$. The genomic DNA was precipitated as a clear layer in the microcentrifuge tube. In this way, genomic DNA was extracted from the blood of the subjects.

\section{PCR Test}

Short preexisting polynucleotide chain to which new deoxyribonucleotides were added by DNA polymerase as a primer. These primers were obtained from a PCR primer kit supplied by Thermo Fisher.

For rs 1005464

BMP2FP1: 5'GAGGGTTTCTGTGAACGTCT3'

BMP2RP1: 5'CATACAAAATTGCCACTATTTGA3'

For rs15705

BMP2FP2: 5'CCCAATGAAGACTTTATTTATGG3'

BMP2RP2: 5'GTAGCACTGCAAAAAAGCAAAC3'

The reaction mixture contains precipitated DNA, DNA polymerase, tris- $\mathrm{HCl}$ buffer solution (to maintain $\mathrm{pH}$ ), $\mathrm{PCR}$ primers $(250 \mathrm{mmol} / \mathrm{L})$, and distilled water (rest volume till $20.0 \mu \mathrm{L}$ ) (reaction medium). Later on, the reaction mixture was subjected to PCR in a PCR machine (AB Applied BioSystem). It was scheduled to rerun the three-staged cycle 35 times. The double-stranded genome was denatured by heat, by disrupting the hydrogen bonds between complementary bases, yielding single-stranded DNA templates at $95^{\circ} \mathrm{C}$ for $3 \mathrm{~min}$, followed by actual denaturation at $95^{\circ} \mathrm{C}$ for $1 \mathrm{~min}$. The primers annealed to the single-stranded DNA template at $58^{\circ} \mathrm{C}$ for $1 \mathrm{~min}$. The DNA polymerase identifies the primer and manufactures a complimentary duplication of the template at $72^{\circ} \mathrm{C}$ for $1 \mathrm{~min}$.

\section{DNA Sequencing}

DNA sequencing was performed using Frederick Sanger's dideoxy sequencing method in an automated $A B I$ sequencer machine (ABI 3730 SeqGen) based on the selective incorporation of chainterminating dideoxynucleotides by DNA polymerase during in vitro DNA replication. The reaction mixture contained obtained PCR products, complimentary primer, DNA polymerase, 4 different dNTPs, 4 different colored fluorochrome-labeled ddNTPs (chain terminators) was heated $\left(96^{\circ} \mathrm{C}\right)$ so that the double-stranded DNA separates into single-stranded DNA. Later, the temperature was reduced to $50^{\circ} \mathrm{C}$ so that the primers bind to the complementary sequence on the new single-stranded DNA. Again, the temperature was raised and DNA polymerase binds to the DNA. Chain synthesis reaction took place until ddNTPs (chain terminators) binds. In this way, strands of DNA of varying lengths were formed.Obtained PCR products after DNA sequencing were subjected to gel electrophoresis using $1.4 \%$ agarose gel with ethidium bromide for separation of base pairs.

For BMP2 rs1005464 variants, three genotypes were possible: A/A normal homozygous allele, A/G mutant heterozygous allele, and G/G mutant homozygous allele. For the BMP2 rs15705 variant, three genotypes were possible: $A / A$ normal homozygous allele, $A / C$ mutant heterozygous allele, and C/C mutant homozygous allele. 
Z-test was used to find the significance of the association of EDA gene polymorphism with dental crowding. It can be applied for qualitative and quantitative data. Here it was applied to test the difference between two proportions.

\section{Results}

In the present study, the relationship between BMP2 rs1005464 and rs15705 gene variants with skeletal class I crowding was evaluated in 60 subjects consisting of group A (P1-P30) and group $B(C 1-C 30)$ as controls using PCR test followed by DNA sequencing.

For BMP2 rs1005464 variants, three genotypes can be possible: A/A normal homozygous allele, $A / G$ mutant heterozygous allele, G/G mutant homozygous allele. Later, the number of cases and controls with specific genotypes has been counted. In group A, 2 out of 30 cases showed the presence of AA genotype, 7 out of 30 cases showed the presence of AG genotype, 21 out of 30 cases showed the presence of GG genotype. In group B, 27 out of 30 controls showed the presence of AA genotype, 2 out of 30 controls showed the presence of AG genotype, 1 out of 30 controls showed the presence of GG genotype (Fig. 1).

After statistical analysis (Z-test), there were statistically significant differences in $A A$ and $G G$ genotypes in cases and controls. The difference in the proportion of positive results between cases and controls for genotype AA and GG was found to be statistically highly significant $(p=0.001)$. The difference in the proportion of positive results between cases and controls for genotype AG was not statistically significant ( $p=0.07$ ) (Table 1).

For the BMP2 rs15705 variant, three genotypes can be possible: A/A normal homozygous allele, $\mathrm{A} / \mathrm{C}$ mutant heterozygous allele, $\mathrm{C} / \mathrm{C}$ mutant homozygous allele. Later, the number of cases and controls with specific genotypes has been counted. In group $A, 7$ out of 30 cases showed the presence of AA genotype, 15 out of 30 cases showed the presence of AC genotype, and 8 out of 30 cases showed the presence of CC genotype. In group B, 19 out of 30 controls showed the presence of AA genotype, 11 out of 30 controls showed the presence of AC genotype, and 0 out of 30 controls showed the presence of CC genotype (Fig. 2).

After statistical analysis (Z-test), there were statistically significant differences in AA and CC genotype frequencies between cases and controls. The difference in the proportion of positive results between cases and controls for genotype AA and CC was found to be statistically highly significant $(p=0.0018, p=0.0024$ respectively). The difference in the proportion of positive results between cases and controls for genotype AC was not statistically significant ( $p=0.29$ ) (Table 2).

\section{Discussion}

Genetics is the science of hereditary and variations of inherited characteristics. The effect of genetic and environmental factors in the etiology of malocclusions represents a subject of splendid value in orthodontics. The higher the genetic part in the etiology of

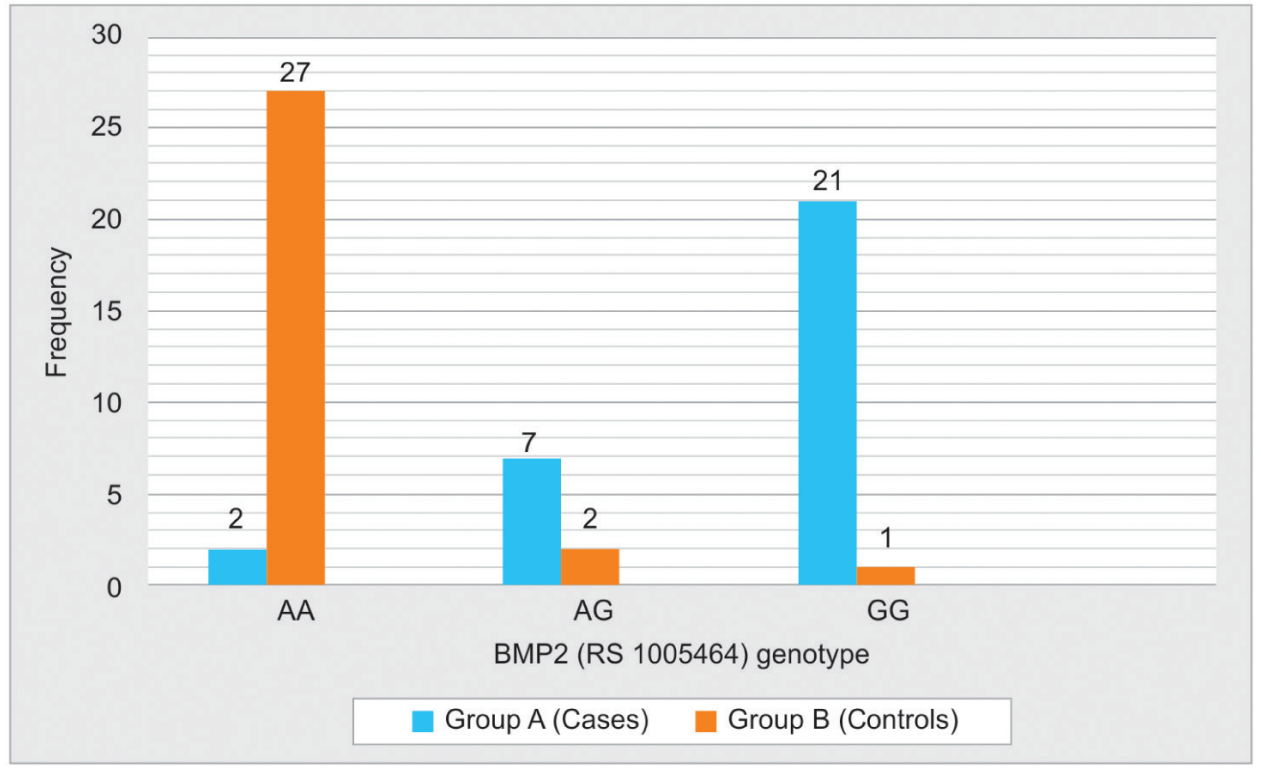

Fig. 1: Varying frequencies of the genotype of BMP2 (rs1005464) gene variant among cases and controls

Table 1: Statistical significance of the genotype (BMP2 ( $r$ 1005464)) when cases and controls are compared using Z-test

\begin{tabular}{llllllll}
\hline $\begin{array}{l}\text { The genotype of } \\
\text { BMP2 (rs1005464) }\end{array}$ & \multicolumn{2}{l}{ Cases } & \multicolumn{5}{l}{ Control } \\
gene variant & $N$ & $\%$ & $N$ & $\%$ & $\begin{array}{l}\text { Difference in } \\
\text { proportion }\end{array}$ & \multicolumn{1}{c}{$Z$} & p-value \\
\hline AA & 2 & $(6.67)$ & 27 & $(90)$ & -0.833 & -6.45 & 0.001 (highly significant) \\
AG & 7 & $(23.33)$ & 2 & $(6.67)$ & 0.166 & 1.81 & 0.07 (not significant) \\
GG & 21 & $(70)$ & 1 & $(3.33)$ & 0.667 & 5.36 & 0.001 (highly significant) \\
\hline
\end{tabular}

$p$-value $<0.05$ indicates statistically significant 


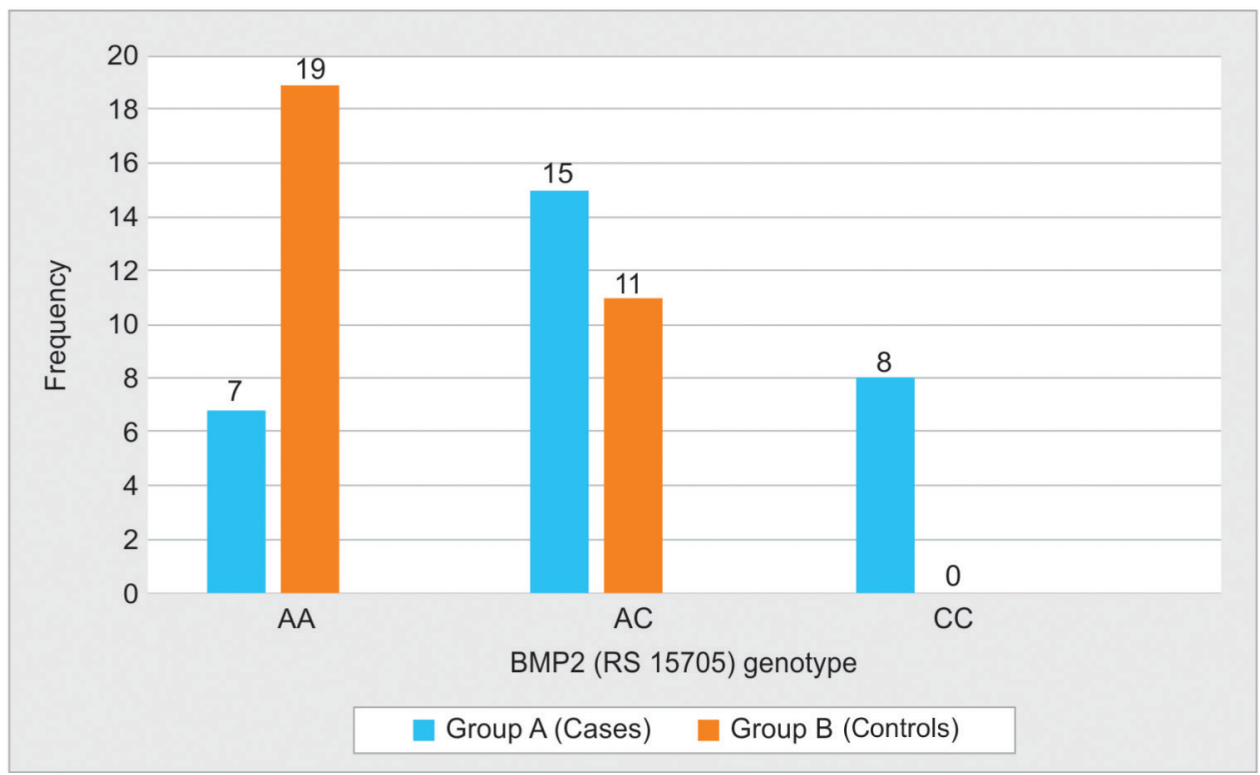

Fig. 2: Varying frequencies of the genotype of BMP2 (rs15705) gene variant among cases and controls

Table 2: Statistical significance of the genotype (BMP2 (rs15705)) when cases and controls are compared using Z-test

\begin{tabular}{|c|c|c|c|c|c|c|c|}
\hline \multirow{2}{*}{$\begin{array}{l}\text { Genotype of BMP2 } \\
\text { (rs15705) gene variant }\end{array}$} & \multicolumn{2}{|c|}{ Cases } & \multicolumn{2}{|c|}{ Control } & \multirow{2}{*}{$\begin{array}{l}\text { Difference in } \\
\text { proportion }\end{array}$} & \multirow[b]{2}{*}{$Z$} & \multirow[b]{2}{*}{$p$-value } \\
\hline & $N$ & $\%$ & $N$ & $\%$ & & & \\
\hline$A A$ & 7 & 23.33 & 19 & 63.33 & 0.433 & -3.12 & 0.0018 (highly significant) \\
\hline$A C$ & 15 & 50 & 11 & 36.67 & 0.133 & 1.04 & 0.29 (not significant) \\
\hline $\mathrm{CC}$ & 8 & 26.67 & 0 & 00 & 0.267 & 3.03 & 0.0024 (highly significant) \\
\hline
\end{tabular}

$p$-value $<0.05$ indicates statistically significant

a dentofacial irregularity, the minor the opportunity of prevention and, generally, of poor quality is the prediction for orthodontic/ orthopedic treatment. ${ }^{9}$

The new guidelines of dental research are directed towards the knowledge of the human genotype. The human genome database assignment was accomplished at the commencement of the 21st era. Advancement in the identification of a particular gene with the localization of its defective gene using genomic studies helps in identifying the underlying factor causing malocclusion in the future. More than a few studies say the genetic and heritable background is responsible for the etiology of dental anomalies and malocclusions, such as skeletal class II pattern, class III pattern, tooth agenesis, microdontia, and canine-sideways transposition. ${ }^{10}$

Dental crowding is a challenge for growth and grown human in the modern era and is a complex anomaly leads to pitiful esthetics and hence, characteristic of life. Crowding is caused by deficient arch space for all permanent teeth. ${ }^{1,11}$ Dental crowding does not prevail as a serious health problem but it may have an effect on occlusal disharmonies with masticatory, esthetic, and speech dysfunctions.

Crowding is a communal dental anomaly like transformation, such as single nucleotide polymorphisms (SNPs) and the "common disease, common variant" hypothesis, stated that SNPs are the chief genetic factor for crowding.

The development of dentition is a fascinating process that encompasses a multifactorial series of epithelial-mesenchymal interactions between developmental growth factors, transcription factors, single receptors, and other morphogens. It is not unexpected that such a multifactorial series is prone to disturbances.
The morphogenesis of altogether epithelial appendages is in harmony by a chain of mutual interactions between the epithelial and mesenchymal tissue components. Teeth are representative examples of epithelial-mesenchymal organs. They build from stomodeal or pharyngeal epithelium and the underlying neural crest-derived mesenchymal cells like skin derivatives, such as hairs, fine hair, and scales. ${ }^{12}$ Various signaling pathways are involved in this interaction, and BMP gene-based signaling factors play an important role. It has been stated that the BMP family are responsible for tooth structure, number, size, and patterning. ${ }^{1,13}$

BMP2 gene is located at the short arm of the 20th chromosome in region 1 and band 2 (20p 12). It causes protein formation, which belongs to the TGF $\beta$ family, and induces bone and cartilage formation by acting as disulfide-linked homodimers. ${ }^{14,15}$ Mutations of this gene can lead to anomalies in the development of ectodermal organs, which include sweat glands, hair follicles, and teeth. ${ }^{2}$

However, only one study has been carried out to find the genetic associations of SNPs related to BMP2, EDA, and XEDAR gene with crowding. ${ }^{2,13-16}$

In our study, we have compared and evaluated the association of SNPs related to the BMP2 gene (rs1005464 and rs15705) with crowding in Bengaluru, Karnataka population. Blood samples were subjected to PCR amplification of the desired segment according to rs1005464 and rs15705 and were then analyzed by DNA sequencing and capillary electrophoresis.

DNA sequencing of human and other genomes has been at the center of attraction in the biomedical field over decades and is straight away leading toward an era of personalized medicine. 
During this time, DNA sequencing methods evolved from intense gel electrophoresis to automated multi capillary electrophoresis systems via fluorophore labeling. Dye-terminator-based gene sequencing allowed four dideoxynucleotide chain terminators, tagged with dyes of different fluorescent emission wavelengths, in a single sequencing reaction which is depicted by a grid called electropherogram or chromatogram. ${ }^{16}$ This grid contains a classification of peaks in four colors that are universally color implicit for every nucleotide (thymine-red, adenine-green, guanine-black, and cytosine-blue). Any swap in natural nucleotide sequencing will be made known as assorted color point and if it is homozygous it will be publicized as a single peak as if it is heterozygous it will be publicized as a double peak.

According to the interpretation of the electropherogram for rs1005464 in group A (cases), 2 subjects showed the presence of AA genotype, 7 subjects showed the presence of AG genotype, and 21 showed the presence of GG genotype. In group B (controls) 27 subjects showed the presence of AA genotype, 2 subjects showed the presence of AG genotype, and only 1 showed the presence of GG genotype. Penetrance in genetics is the proportion of individuals carrying a particular variant of a gene (allele or genotype) that furthermore expresses a linked trait (phenotype). In medicinal genetics, the penetrance of a disease-causing mutation is the proportion of individuals with the mutation who exhibit clinical symptoms. Penetrance is assumed to be cut-rate or short after more or fewer persons fail to express the trait, even though they transmit the allele. Incomplete penetrance can be a reason for having mutant allele but clinically showed absence of crowding

After statistical analysis of all 60 subjects for rs1005464, we concluded that there was a significant difference between the AA and GG alleles in cases and controls. AA genotype was found to be strongly associated with controls (group B) $(p=0.001)$ while GG genotype was found to be strongly associated with cases (group A) $(p=0.001)$. AG genotype was not associated with either control (group B) or cases (group A) ( $p=0.07)$. This is claimed by the study conducted on Hong Kong Chinese population by Ting et al. ${ }^{2}$

According to the interpretation of electropherogram of 60 subjects, for $r$ 15705, in group A, 7 subjects showed the presence of AA genotype, 15 subjects showed the presence of AC genotype, and 8 subjects showed the presence of CC genotype. In group $B$, 19 subjects showed the presence of AA genotype, 11 subjects showed the presence of AC genotype, and none of them showed the presence of CC genotype. Incomplete penetrance can be a cause of AC genotype not leading to crowding (phenotype).

After statistical analysis of all 60 subjects for rs15705, we concluded that there was a significant difference between $A A$ and $C C$ alleles between cases and controls. AA allele was found to be strongly associated with controls (group B) $(p=0.0018)$ while CC genotype was found to be strongly associated with cases (group A) $(p=0.0024)$. AC genotype was not associated with either case (group A) or controls (group B) $(p=0.29)$. This is also claimed by the study conducted on Hong Kong Chinese population by Ting et al. where this SNP showed a marginal association. ${ }^{2}$

The findings of this study indicated that variants of the BMP2 gene rs1005464 and rs15705 polymorphisms might be a genetic marker for skeletal class I crowding in our population. This study was conducted in a limited region with limited sample size. Only one gene was targeted in this study. Further studies, targeting a large sample size and several genes are required for better insight and understanding of the complex genetics of skeletal class I crowding. A meta-analysis in a wider extent of patient groups with a more complete clinical description of affected individuals may be required to further utterly portray the society between genetic markers and skeletal class I crowding cases. A most important challenge is not simply cataloging of every gene but furthermore identification of their polygenetic nature on dental crowding.

\section{Conclusion}

With the new DNA sequencing and microarray techniques, advanced identification of the candidate gene and genetic pathways involved in skeletal class I crowding can be expected. Shortly, with prompt advances in the science of DNA manipulation, the correction or alteration of genetic defects at the molecular level remains a possibility. Gene manipulation can be employed to command the expression of any DNA most orthodontically-related issues. In turn, we may witness the introduction of both preventive and in vivo fetal therapy for this malocclusion.

\section{References}

1. Graber TM, Vanarsdall RL. Orthodontics: Current Principles and Techniques. St Louis: Mosby-Year Book; 1994.

2. Ting TY, Wong RWK, Rabie ABM. Analysis of genetic polymorphisms in skeletal class I crowding. Am J Orthod Dentofacial Orthop 2011;140(1):e9-e15. DOI: 10.1016/j.ajodo.2010.12.015.

3. Baker CR. Similarity of malocclusion in families. Int J Orthod 1924;10(8):459-462. DOI: 10.1016/S0099-6963(24)90032-9.

4. Korkhaus G. Anthropologic and odontologic studies of twins. Int J Orthodont 1930;16(6):640-647. DOI: 10.1016/S0099-6963(30)90323-7.

5. Corruccini RS, Potter RH. Genetic analysis of occlusal variation in twins. Am J Orthod 1980;78(2):140-154. DOI: 10.1016/00029416(80)90056-1.

6. Mavropoulos A, Kiliaridis S. Orthodontic literature: an overview of the last 2 decades. Am J Orthod Dentofacial Orthop 2003;124(1):30-40. DOI: 10.1016/s0889-5406(03)00199-9.

7. Human genome. International Human Genome Consortium: Initial sequencing and analysis of the human genome. Nature 2001;409:860-921.

8. Baik CY, Ververidou M. A new approach of assessing sagittal discrepancies: the beta angle. Am J Orthod 2004;126(1):100-105. DOI: $10.1016 /$ S0889540604002483.

9. Vaahtokari A, Aberg T, Jernvall J. The enamel knot as a signalling center in the developing mouse tooth. Mech Dev 1996;54(1):39-43. DOI: 10.1016/0925-4773(95)00459-9.

10. Garib DG. Associated dental anomalies: the orthodontist decoding the genetics which regulates the dental development disturbances. Dental Press J Orthod 2010;15(2):138-157.

11. Wei F, Vergnes J, Vergnes JN, et al. Asynchronous dentofacial development and dental crowding: a cross-sectional study in a contemporary sample of children. J Physiol Anthropol 2013;32(1):22. DOI: 10.1186/1880-6805-32-22.

12. Cobourne MT. The genetic control of early odontogenesis. Br J Orthod 1999;26(1):21-28. DOI: 10.1093/ortho/26.1.21.

13. Feng J, Yang G, Yuan G. Abnormalities in the enamel in BMP2deficient mice. Cells Tissues Organs 2011;194(2-4):216-221. DOI: 10.1159/000324644.

14. Matsumoto T, Yamada A, Aizawa R, et al. BMP-2 induced expression of Alx 3 that is a positive regulator of osteoblast differentiation. PLoS One 2013;8(6):e68774. DOI: 10.1371/journal.pone.0068774.

15. Miyoshi K, Nagata H, Horiguchi T, et al. BMP2-induced gene profiling in dental epithelial cell line. J Med Invest 2008;55(3-4):216-226. DOI: 10.2152/jmi.55.216.

16. Dolnik D. DNA sequencing by capillary electrophoresis (review). J Biochem Biophys Methods 1999;41(2-3):103-119. DOI: 10.1016/S0165022X(99)00041-X. 